http://jmscr.igmpublication.org/home/ ISSN (e)-2347-176x ISSN (p) 2455-0450 crossref DOI: https://dx.doi.org/10.18535/jmscr/v9i9.17

\author{
Journal Of Medical Science And Clinical Research

$\underline{\text { Research Article }}$

\title{
Polycystic ovary syndrome: Relationship between serum Anti mullerian hormone (AMH) and other reproductive hormones
}

\author{
Authors \\ Dr Meenakshi Rana ${ }^{1}$, Dr Kamini Randhawa ${ }^{2}$ \\ ${ }^{1}$ Junior Resident, Department of Obstetrics and Gynaecology, IGMC Shimla \\ 2 Junior Resident, Department of Aneasthesiology, IGMC Shimla
}

\begin{abstract}
Objective: To examine the relationship of serum anti mullerian hormone (AMH), FSH, free-T, LH, and TSH in women with polycystic ovary syndrome (PCOS).

Design: A prospective observational study.

Setting: Departments of Obstetrics and Gynecology IGMC Shimla.

Patient(s): 50 women with PCOS and 50 non PCOS women.

Intervention(s): blood samples were collected on day 2 of menstrual cycle and analysed.

Main Outcome Measure(s): Serum levels of FSH, LH, free-T, TSH, Prolactin, AMH were measured.

Result(s): Serum Anti Mullerian hormone levels were significantly higher in PCOS patients as compared to non PCOS patients. $\left(7.58+\_3.93 \mathrm{ng} / \mathrm{mL}\right.$ and $2.89+\_1.19 \mathrm{ng} / \mathrm{ml}$ respectively).

PCOS patients had higher serum LH levels than non pcos patients $\left(10.04+\_2.6 \mathrm{mIU} / \mathrm{mL}\right)$.

Conclusion: In this study, PCOS patients have significantly higher serum AMH levels than non PCOS. And serum LH levels were also higher in PCOS group.

Keywords: Antimullerian hormone (AMH), polycystic ovary syndrome (PCOS).
\end{abstract}

\section{Introduction}

Polycystic ovary syndrome (PCOS) is one of the most common endocrine disorders in women of reproductive age ${ }^{(1)}$. PCOS is also a leading cause of oligomenorrhea and infertility due to anovulation. The PCOS prevalance in the general population has been reported in between $2 \%$ $20 \%$, depending upon the criteria which are used to define it. Polycystic ovaries despite being a common clinical feature, are not pesent in some patients with hyperandrogenic oligomenorrhea/ anovulation $^{(3-6)}$. There is high risk for developing dysfunctional uterine bleeding, endometrial carcinoma, diabetes mellitus, hypertension, dyslipidemia, insulin resistance, and cardiovascular disease ${ }^{(2)}$. Sometimes young women presenting with this ovarian morphology, do not possess typical PCOS characteristics ${ }^{(3)}$. Some essential features of PCOS include arrested folliculogenesis leading to multiple small antral follicles, low serum FSH levels, elevated serum $\mathrm{LH}$, and hyperandrogenism both biochemical and clinical $^{(2)}$. The exact etiology of PCOS is not well understood. The pathogenesis of PCOS is suggested to be multifactorial and not attributed to a single causative agent ${ }^{(1)}$. It is suggested that failure of FSH-dependent follicular maturation lead to anovulation, which is a thought to be the 
common pathway leading to disordered folliculogenesis $^{(2)}$. Failure of FSH action is not known, but some local ovarian hormones may play role. These hormone includes inhibins ${ }^{(7,8)}$, $\operatorname{activin}^{(7)}$, transforming growth factor ${ }^{(9,10)}$, tumor necrosis factor ${ }^{(11,}{ }^{12)}$, and antimullerian hormone $(\mathrm{AMH}){ }^{(13-15)}$. anti mullerian hormone is produced in ovaries by granulosa cells of ovarian follicles during the reproductive period ${ }^{(16)}$.

$\mathrm{AMH}$ is thought to decreased aromatase activity in the fetal ovary ${ }^{(17)}$. AMH inhibits oocyte meiosis in rat ovary in vitro ${ }^{(13)}$, as well as granulosa-luteal cell proliferation and $\mathrm{P}$ production ${ }^{(18)}$. AMH concentrations correlated with a number of immature oocytes, more the immature follicles higher are the levels of AMH. This supports that AMH suppresses oocyte maturation ${ }^{(13)}$. Also a recent study showed that serum AMH levels fluctuate during the menstrual cycle, suggesting that $\mathrm{AMH}$ may have a regulatory role in folliculogenesis ${ }^{(19)}$. In this study, we examine the relationship between serum AMH levels and $\mathrm{S}$ testosterone and gonadotropins (FSH and $\mathrm{LH}$ ) in women with PCOS and without PCOS.

\section{Materials and Methods}

This prospective observational study was conducted in the department of Obstetrics and gynaecology at Kamla Nehru State Hospital for Mother and Child IGMC Shimla from 1st july 2018 to 30th june 2019. During a 12-month period, a total of 100 women with irregular menstrual cycles were included in this study after taking an informed consent. The inclusion criteria were women with age between 15-35 yr, having both ovaries, with history of menstrual irregularities, history of hyperandrogenism. After taking informed consent from all the women detailed history was taken followed by general physical and systemic examination. On day 2 of menstrual cycle a rouitne gynecological examination performed followed by ultrasonography and individual patient was assigned to a group according to the presence of the symptoms. Then AMH levels of the patients done on Day2 of menstrual cycle. From these 100 women , 50 women were assigned PCOS group, on the basis of the following criteria: presence of (1) oligomenorrhea/anovulation

hyperandrogenism (biochemical and clinical) (3) presence of polycycstic ovarian morphologhy . To exclude thyroid dysfunction as the cause of the oligomenorrhea serum TSH levels were done. To rule out hyperprolactinemia as a cause of hyperandrogenism serum prolactin levels were done.

50 patients who had either regular menstrual cycles (menses every 21-35 days) or irregular menstrual cycle who do not meet the criteria of PCOS were included as the control group that is non PCOS group. Serum LH and FSH levels were determined using an enzyme immunoassay. Serum testosterone levels were measured and used to define hyperandrogenemia in the PCOS women when the levels were above the 75th percentile of the levels for the women in the non PCOS group.Serum AMH concentrations were measured by $\operatorname{ELISA}^{(15)}$. Statistical analysis was done using SPSS. Data was entered into SPSS and analysed. For qualitative variables frequency/percentage was calculated and for quantitative variables mean/ standard deviation was calculated.

\section{Results}

In PCOS group age of the patients was between 25-30 years and in non PCOS group was between 20-25 years. Mean age of the two groups was similar. The mean body mass index (BMI) was higher in the PCOS group $\left(27.1+_{-} 1.5\right)$. NonPCOS group had maximum patients in normal weight band as compared to PCOS group. However in PCOS group maximum patients were obese.

Table 1 shows the serum levels of gonadotropins in PCOS group and non PCOS group. The mean serum level of LH in PCOS group was significantly higher compared with non pcos group ( $P$ value $<0.001$ ). Serum FSH levels were not significantly different in the two groups. Serum levels of free-T in PCOS group were 
higher $(P$ value $<0.001)$ as compared to non PCOS group. The mean serum prolactin levels in the PCOS women were $11.4+\ldots 4.0 \mathrm{ng} / \mathrm{mL}$ and were within normal range $(2-15 \mathrm{ng} / \mathrm{mL})$. The serum levels of AMH in PCOS group were significantly higher than non PCOS group. Mean serum concentrations were $7.58+3.93$ in PCOS group and 2.89+_1.19 ng/mL, respectively $(P$ $<0.001)$. Linear regression analysis of serum $\mathrm{AMH}$ and other hormones was carried out. No correlation existed between $\mathrm{AMH}$ and all hormones levels either in PCOS or Non PCOS group.

Table 1

\begin{tabular}{|l|c|c|c|}
\hline & PCOS & NON PCOS & pvalue \\
\hline FSH & $4.30+\_1.6$ & $5.36+\_1.62$ & $<0.05$ \\
\hline LH & $10.04+\_2.6$ & $2.44+\_0.74$ & $<0.001$ \\
\hline FT & $1.50+\_1.2$ & $3.16+\_0.89$ & $<0.001$ \\
\hline TSH & $2.30+\_0.56$ & $2.13+\_1.2$ & $>0.05$ \\
\hline PROLACTIN & $11.40+\_4.0$ & $11.62+\_3.5$ & $>0.05$ \\
\hline
\end{tabular}

Table 2

\begin{tabular}{|c|c|c|c|}
\hline & PCOS & NON PCOS & P value \\
\hline AMH & $7.58+\_3.93$ & $2.89+\_1.19$ & $<0.001$ \\
\hline
\end{tabular}

\section{Discussion}

PCOS is a wide spectrum disorder. PCOS patients usually present with symptoms of oligomenorrhea/anovulation, hyperandrogenemia both clinical and biochemical and/or obesity ${ }^{(2)}$. Not all patients have the typical clinical syndrome. Usually anovulation is expressed as oligomenorrhea and irregular menstrual cycle and hyperandrogenism present as hirsutism.

Obesity is now recognized in the variants of PCOS, particularly in the early stages of the disorder. PCOS may be diagnosed in adolescents and young women eeven when the symptoms are not fully expressed ${ }^{(20,21)}$. In our study all of our women with PCOS are with irregular menstrual cycle or oligomenorrhea and all are hyperandrogenic either clinically or biochemically.

The exact pathogenesis of this disorder is not well explained, but after the initial recruitment of follicles there is distinctive failure of follicular maturation in polycystic ovaries indicating disruption in normal hormonal activities ${ }^{(2)}$. The essential features in PCOS women is arrested folliculogenesis. Maintenance of normal ovarian function depend upon gonadotropins and steroids. Hence PCOS is associated with low or low normal serum FSH levels, high or high-normal serum LH, and hyperandrogenism ${ }^{(2)}$.

Our prospective study indicate that serum AMH levels are significantly higher in PCOS patients than in non PCOS patients. It is suggested that AMH can decrease aromatase activity ${ }^{(17)}$, so AMH may have a role in the dysregulation of steroidogenesis in PCOS.

The exact pathway of AMH activity is not kknown. The hypothalamic-pituitary-gonadal axis has no influence on action of $\mathrm{AMH}$ on activity of ovaries. AMH and inhibins A and B are glycoprotein hormones and belong to same transforming growth factor supergene family having regulatory influences on ovarian activity $(22,23)$

Other studies also showed that in PCOS patients, obesity has influence on serum hormone levels. In our prospective study, obesity is defined by BMI, had no or minimal influence on serum AMH levels. Levels of LH were higher in PCOS patients as compared to non PCOS patients. Serum AMH levels were higher in PCOS patients as compared to non PCOS patients. This may be due to the aberrant activities of the granulosa cells induced by unknown factors in the polycystic ovaries. Serum AMH levels has been proved to be useful in the evaluation of some slected patients having sex cord tumors or granulosa cell tumors ${ }^{(24,25)}$, and can be used as a predictive marker of persistent or recurrent disease ${ }^{(26)}$. The serum levels of AMH in oligomenorrhea/anovulation may also prove to be a helpful as a tool in the diagnosis of PCOS in women.

\section{References}

1. Knochenhauer ES, Key TJ, Kahsar-Miller M, Waggoner W, Boots LR, Azziz R. Prevalence of the polycystic ovary syndrome in unselected black and white 
women of the Southeastern United States: a prospective study. J Clin Endocrinol Metab 1998;83:3078-82.

2. Yen SSC. Polycystic ovary syndrome: hyperandrogenic chronic anovulation.In: Yen SSC, Jaffe RB, Barbieri RL, eds. Reproductive endocrinology, physiology, pathophysiology and clinical management, $4^{\text {th }}$ ed. Philadelphia: WB Saunders, 1999:436-78.

3. Michelmore KF, Balen AH, Dunger DB, Vessey MP. Polycystic ovaries and associated clinical and biochemical features in young women. Clin Endocrinol 1999;51:779-86.

4. Orsini LF, Ventruroli S, Lorusso R, Pluchinotta V, Paradisi R, Bovicelli L. Ultrasonic findings in polycystic ovarian disease. 1985;43:709-14.

5. El Tabbakh GH, Lotfy I, Azab I, Rahman HA, Southren AL, Aleem FA. Correlation of the ultrasonic appearance of the ovaries in polycystic ovarian disease and the clinical, hormonal, and laparoscopic findings. Am J Obstet Gynecol 1986;154:892-5.

6. Polson DW, Wadsworth J, Adams J, Franks S. Polycystic ovaries - a common finding in normal women. Lancet 1988;1:870-2.

7. Roberts VJ, Barth S, el-Roeiy A, Yen SS. Expression of inhibin/activin system messenger ribonucleic acids and proteins in ovarian follicles from women with polycystic ovarian syndrome. J Clin Endocrinol Metab 1994;79:1434-9.

8. Jaatinen TA, Penttila TL, Kaipia A, Ekfors T, Parvinen M, Toppari J. Expression of inhibin alpha, beta $A$ and beta $B$ messenger ribonucleic acids in the normal human ovary and in polycystic ovarian syndrome. J Endocrinol 1994; 143:12737.

9. Hernandez ER, Hurwitz A, Payne DW, Dharmarajan AM, Purchio AF, Adashi
EY. Transforming growth factor-_1 inhibits ovarian androgen production: gene expression, cellular localization, mechanism(s), and site(s) of action. Endocrinology 1990;127:2804-11.

10. Chegini N, Flanders KC. Presence of transforming growth factor beta and their selective cellular localization in human ovarian tissue of various reproductive stages. Endocrinology 1992;130:1707-15.

11. Roby KF, Terranova PF. Effects of tumor necrosis factor-alpha in vitro on steroidogenesis of healthy and atretic follicles of the rat: theca as a target. Endocrinology 1990;126:2711-8.

12. Andreani CL, Payne DW, Packman JN, Resnick LF, Hurnitz A, Adashi EY. Cytokine-mediated regulation of ovarian function. Tumor necrosis factor-alpha inhibits gonadotropin-supported ovarian androgen biosynthesis. J Biol Chem 1991;266:6761-6.

13. Takahashi M, Koide S, Donahoe. Mu"llerian inhibiting substance as oocyte meiosis inhibitor. Mol Cell Endocrinol 1986;47:225-34.

14. Ueno S, Kuroda T, MacLaughlin DT, Ragin RC, Manganaro TF, Donahoe PK. Mullerian inhibiting substance in the adult rat ovary during various stages of the estrous cycle. Endocrinology 1989;125: 1060-6.

15. Fallat ME, Siow Y, Marra M, Cook C, Carrillo A. Mu“llerian inhibiting substance in follicular fluid and serum-a comparison of patients with tubal factor infertility, polycystic ovarian syndrome and endometriosis. Fertil Steril 1997;67:962-5.

16. Lee MM, Donahoe PK. Müllerian inhibiting substance: a gonadal hormone with multiple functions. Endocr Rev 1993;14:152-64.

17. di Clemente N, Ghaffari S, Pepinsky R, Pieau C, Josso N, Cate RL, et al. A 
quantitative and interspecific test for biological activity of anti- Mullerian hormone: the fetal ovary aromatase assay. Development 1992;114:721-7.

18. Kim JH, Seibel MM, MacLaughlin DT, Donahoe PK, Ransil BJ, Hametz PA, et al. The inhibitory effects of Mu"llerianinhibiting substance on epidermal growth factor induced proliferation and progesterone production of human granulosa-luteal cells. J Clin Endocrinol Metab 1992;75:911-7.

19. Cook CL, Siow Y, Taylor S, Fallat ME. Serum Mu“llerian inhibiting substance levels during normal menstrual cycle. Fertil Steril 2000;73: 859-61.

20. Moll GW Jr, Rosenfield RL. Plasma free testosterone in the diagnosis of adolescent polycystic ovary syndrome. J Pediatr 1983;102:461-4.

21. Emans SJ, Grace E, Woods ER, Mansfield J, Crigler JF Jr. Treatment with dexamethasone of androgen excess in adolescent patients. J Pediatr 1988;112: 821-6.

22. Muttukrishna S, Fowler PA, Groome NP, Mitchell GG, Robertson WR, Knight PG. Serum concentrations of dimeric inhibin during spontaneous human menstrual cycle and after treatment with exogenous gonadotrophin. Human Reprod 1994; 9:1634-42.

23. Lockwood GM, Muttukrishna A, Ledger WL. Inhibins and activins in human ovulation, conception and pregnancy. Hum Reprod Update1998;4:284-95.

24. Gustafson ML, Lee MM, Scully RE, Moncure AC, Hirakawa T, Goodman A, et al. Mu“llerian inhibiting substance as a marker for ovarian sex-cord tumor. $\mathrm{N}$ Engl J Med 1992;326:466-71.

25. Gustafson ML, Lee MM, Asmundson L, MacLaughlin DT, Donahoe PK. Mu* llerian inhibiting substance in the diagnosis and management of intersex and gonadal abnormalities. J Pediatr Surg 1993;28:439-44.

26. Lane AH, Lee MM, Fuller AF Jr, Kehas DJ, Donahoe PK, MacLaughlin DT. Diagnostic utility of Mu“llerian inhibiting substance determination in patients with primary and recurrent granulosa cell tumors. Gynecol Oncol 1999;73:51-5. 